Part of Journal of Research of the National Bureau of Standards, Volume 28, May 1942

\title{
IMPROVED INSTRUMENT FOR MEASURING THE AIR PERMEABILITY OF FABRICS
}

\author{
By Herbert F. Schiefer and Paul M. Boyland
}

\section{ABSTRACT}

This paper describes a new model of an instrument for the direct measurement of the air permeability of fabrics. The air, which is drawn through the fabric by a given suction, is measured with orifice-type flowmeters. The instrument is mounted in the top of a table and a new clamping device is provided, which permit measurements to be made rapidly on any part of a large piece of cloth without cutting.

The calibration and operation of the instrument are discussed. Results of measurements on two very different types of fabrics - parachute cloth and blankets-are given for several methods of clamping. A suitable method is described for which the edge leakage is negligible. The random sampling error of the average of 5 tests for air permeability is less than 5 percent approximately 9 times out of 10 .

\section{CONTENTS}

I. Introduction

II. Description of the new instrument and its operation

III. Calibration _. 639

1. Inclined manometer... 639

2. Orifices for measuring air flow

IV. Results 640

\section{INTRODUCTION}

Since publication of a description of the portable instrument for measuring air permeability of fabrics, ${ }^{1}$ the instrument has been improved in a number of ways. It has been mounted on a table and provided with clamps which permit the testing of any part of a piece of cloth without cutting. ${ }^{2}$ The duplicability of tests, the variability of air permeability within fabrics, and the effect of the method of clamping have been investigated. The new model is described in this paper, the calibration is discussed, and the results of work with it are given.

\section{DESCRIPTION OF THE NEW INSTRUMENT AND ITS OPERATION}

The instrument, before the fabric is inserted for a test, is shown in figure 1. Figure 2 shows the instrument during a test, and figure 3

\footnotetext{
1 BS J. Research 6, 51-58 (1931) RP261.

2 W. H. Dietrich, chief engineer, Duplan Corporation, Hazelton, Pa., and S. W. Frazier, 953 Fifteenth Street SE., Washington, D. C., made important contributions toward the development of the table-mounted air-permeability instrument.
} 
indicates the essential parts diagrammatically. The orifice over which the fabric is placed is mounted in the top of a table. The area of the opening is $0.0412 \mathrm{ft}^{2}$, the same as in the older model (see footnote 1). A ring weighing $3 \mathrm{lb}$ and having a beveled surface with an inside diameter of 5 in. fits over a similar beveled surface of the orifice rim. The beveled ring is placed over the fabric to hold it across the orifice in a smooth condition and with a slight tension in all directions. This ring is applicable to the testing of fabrics as thick as blankets and as thin as parachute cloth. It can be dispensed with in testing fabrics which are stiff enough to remain flat when placed over the orifice.

The clamp for holding the fabric against the orifice is pivoted in its supporting frame so that it will press uniformily against the upper surface of the orifice. The frame is hinged at the back of the table and locks at the front. It can be raised to permit cloth to be drawn from a bolt across the orifice.

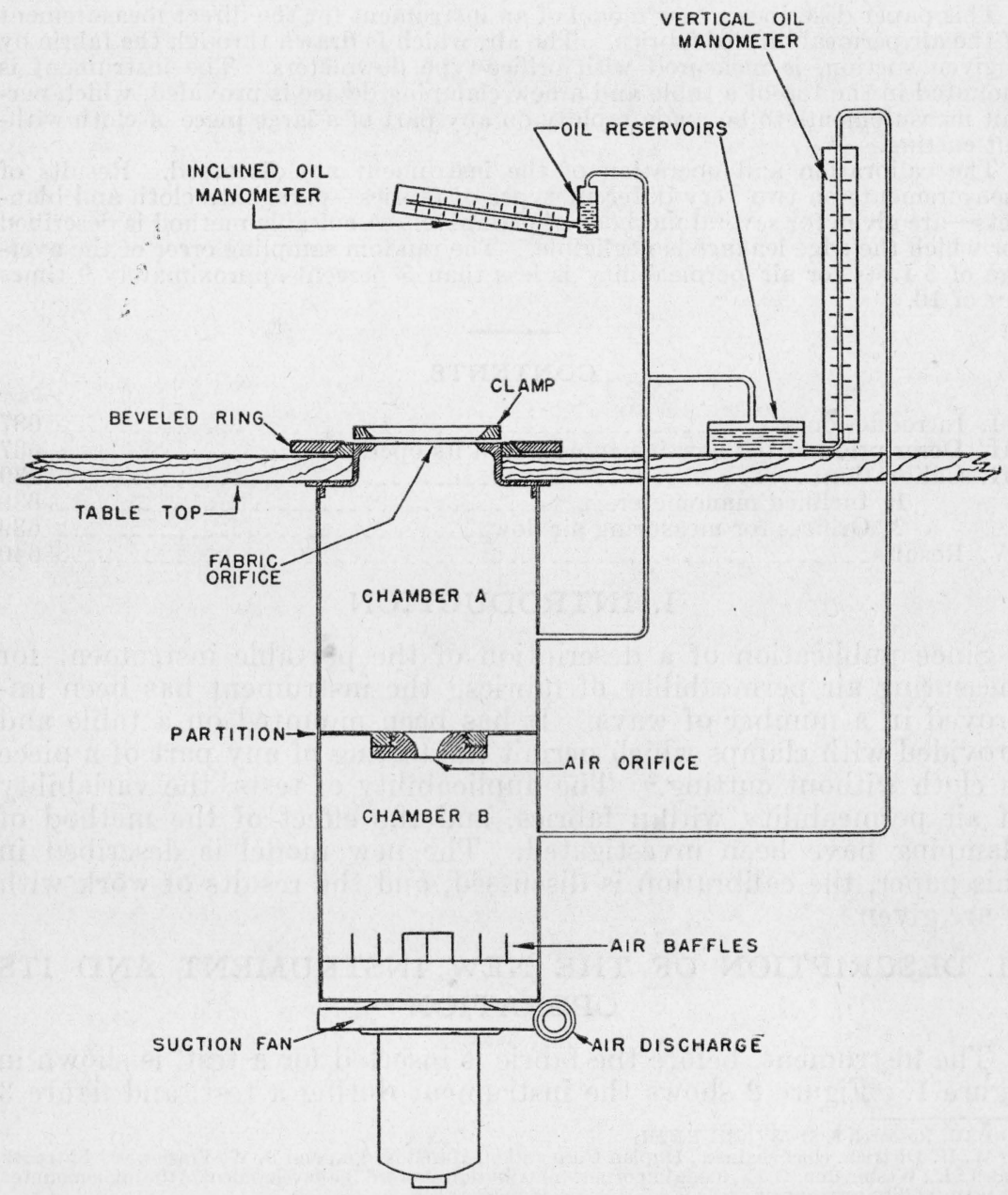

FIGURE 3.-Schematic diagram of the air-permeability instrument. 


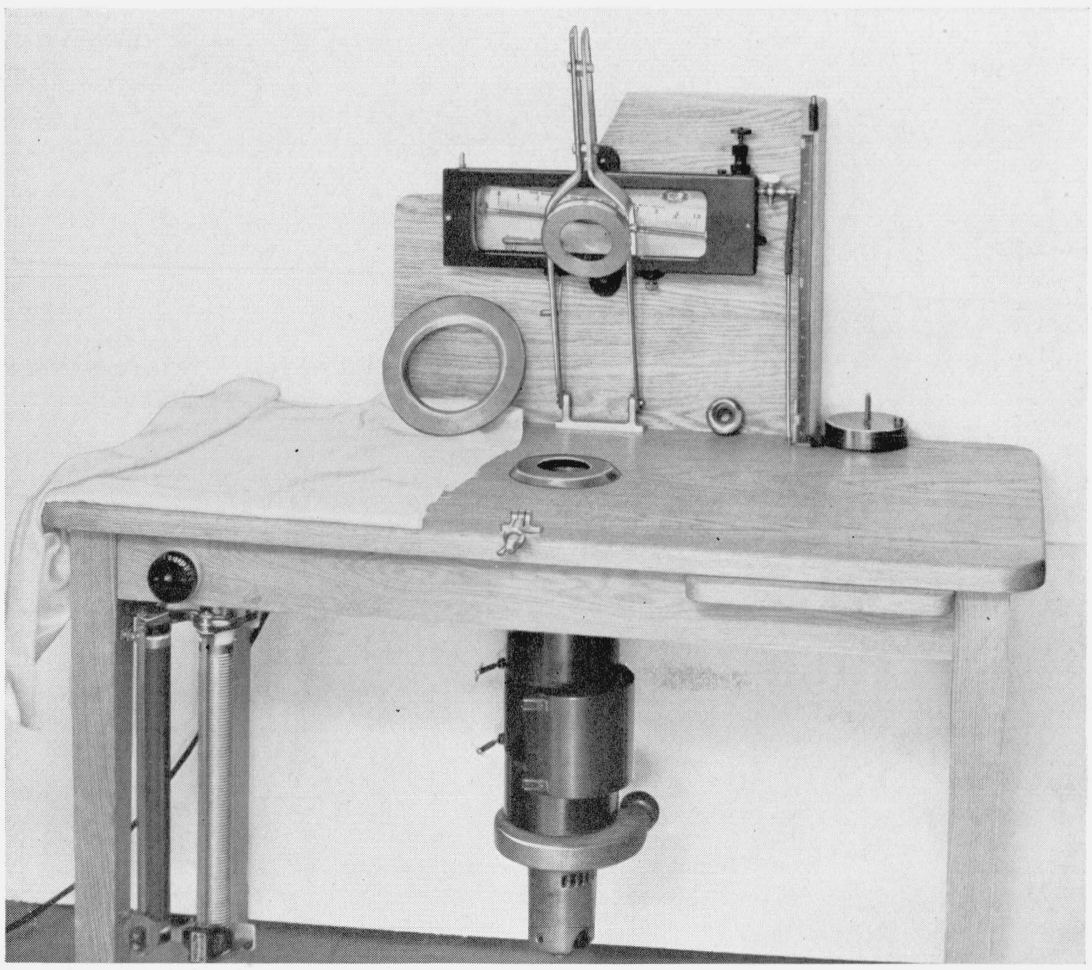

Figure 1.-Air-permeability instrument. 


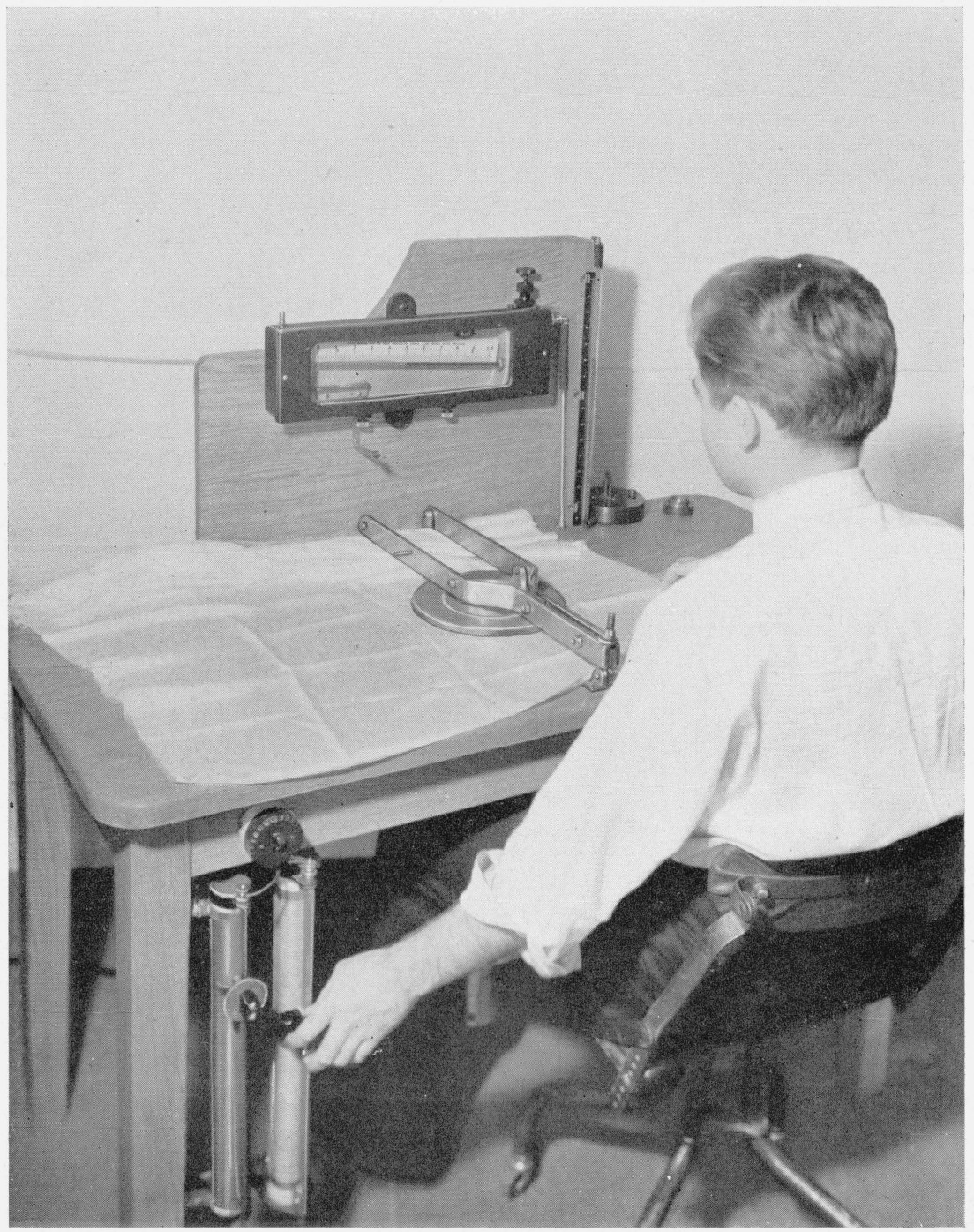

FiguRE 2.-Air-permeability instrument during a test on a fabric. 
The speed of the motor which draws air through the area of fabric under test is adjusted by two rheostats, one of high resistance to obtain rapid changes in speed and one of low resistance for fine adjustment.

Manometers filled with a special oil furnished with the instrument are used to indicate the pressure drops across the fabric under test and across the orifice for measuring the air flow. The inclined manometer, which indicates the pressure drop across the fabric, is provided with leveling screws and a micrometer plunger for adjusting the meniscus to zero when no air is being drawn through the fabric. This manometer functions smoothly and dependably and is a great improvement over the water manometer formerly used, which was very sluggish in operation and had to be cleaned frequently. The vertical manometer, which indicates the pressure drop across the orifice for measuring the air flow, is connected to a reservoir having a large area compared with the cross-sectional area of the manometer so that the oil level in the reservoir remains sufficiently constant.

The amount of air flowing through a fabric under test is determined from the pressure drop indicated by the vertical manometer and the calibration of the orifice which is used. A set of nine orifices covers the range of air permeability from 1 to 700 cubic feet per minute per square foot of fabric. The orifices are easily inserted through a door opening into chamber $B$ of figure 3 . The door is partially open in figure 1 .

The air permeability is usually measured for a pressure drop across the fabric of 0.5 in. of water, but it may be measured at any pressure drop between 0.1 and 1.0 in. of water or at a series of pressure drops between these limits. The appropriate size of orifice to use for a fabric whose approximate air permeability is not known is determined by a trial run. The pressure drop indicated by the vertical manometer should be greater than 3 in. If it is less, a smaller orifice should be used to obtain precision in the measurement.

The top of the table provides space for the excess fabric of a large piece during a test. A sliding leaf is provided for the data sheet. The manometers are mounted so that they can be read easily by the operator seated in front of the instrument.

\section{CALIBRATION}

\section{INCLINED MANOMETER}

The inclined manometer is graduated to read pressure in inches of water, one division equaling a pressure difference of $0.01 \mathrm{in}$. of water. The scale is readily readable to 0.002 in. of water. The pressures indicated by the scales of eight inclined manometers were checked against the values obtained with a sensitive differential pressure gage. The average difference of 30 comparisons, neglecting the algebraic sign, was 0.003 in. of water.

\section{ORIFICES FOR MEASURING AIR FLOW}

Each orifice was calibrated while in place in the instrument. In making the calibration, a given volume of air, measured by means of a calibrated gasometer, was drawn through the instrument. The pressure drop across the orifice, as indicated by the vertical manom- 
eter, was maintained at a constant value during this period. The time required to discharge this volume of air, the pressure of the air at the inlet to the orifice, the pressure drop across the orifice, and the barometric pressure, temperature, and relative humidity of the air in the room were noted. This process was repeated for three additional pressure drops across the orifice. The results were computed to $70^{\circ}$ $\mathrm{F}$, 65-percent relative humidity, barometric pressure of $30 \mathrm{in}$. of $\mathrm{Hg}$, and an area of $1 \mathrm{ft}^{2}$ of fabric. The flow of air through each orifice expressed in cubic feet per minute per square foot of fabric, was calculated for each inch of the vertical manometer scale between 1 and $15 \mathrm{in}$. The uncertainty of these values is about \pm 0.5 percent.

The approximate air permeabilities which can be measured with each of the nine orifices are given in table 1. The flows through orifices of the same diameter supplied with different instruments were found to agree within about 2 percent. The values given in table 1 can be used safely for selecting the size orifice for a given air permeability range.

TABLE 1.-Nominal sizes of the orifices and approximate air-permeability ranges of fabric

\begin{tabular}{|c|c|}
\hline $\begin{array}{l}\text { Diameter of } \\
\text { orifice }\end{array}$ & $\begin{array}{l}\text { Air-permeability } \\
\text { range }\end{array}$ \\
\hline $\begin{array}{r}m m \\
1.0 \\
1.4 \\
2.0 \\
3.0 \\
4.0 \\
6.0 \\
8.0 \\
11.0 \\
16.0\end{array}$ & $\begin{array}{c}(c u f t / \min ) / s q f t \\
1 \text { to } 2.5 \\
2.5 \text { to } 4.5 \\
4.5 \text { to } 10 \\
10 \text { to } 20 \\
20 \text { to } 40 \\
40 \text { to } 100 \\
80 \text { to } 170 \\
160 \text { to } 320 \\
320 \text { to } 700\end{array}$ \\
\hline
\end{tabular}

Tests for air permeability should be made in a room in which the temperature and relative humidity are maintained close to $70^{\circ} \mathrm{F}$ and 65-percent relative humidity, respectively. The specimen should be in equilibrium with this atmosphere at the time of the test.

\section{RESULTS}

The air permeabilities of three parachute cloths and of three blankets were measured in a number of locations, using the beveled ring and clamp for holding the fabric. The average of five independent measurements on the same area and the standard error are reported in table 2 . The average air permeability for each material and the coefficient of variation are also given in table 2 . The results of an analysis of variance of the data indicated highly significant differences with respect to location of the specimens in the fabrics. Obviously, it is advisable to test at more locations in a piece of cloth rather than to make duplicate measurements on a specimen. Using the proposed recommended practice of Committee D-13 of the American Society for Testing Materials for calculating the number of tests, ${ }^{3}$ it follows that the random sampling error of the average of 5 tests for air permeability should not exceed 5 percent approximately 9 times out of 10 .

\footnotetext{
${ }^{3}$ ASTM Standards on Textile Materials, p. 278-288 (October 1941).
} 
TABLE 2.-Air permeabilities of two types of textile fabrics

[Cubic feet per minute per square foot of fabric for a pressure drop of $0.5 \mathrm{in}$. of water across the fabric]

\begin{tabular}{|c|c|c|c|c|c|c|}
\hline \multirow{2}{*}{ Type of material } & \multicolumn{3}{|c|}{ Parachute cloth } & \multicolumn{3}{|c|}{ Blanket } \\
\hline & $\mathbf{I}$ & II & III & IV & V & VI \\
\hline Location number: & $\begin{array}{r}88.2 \pm 1.5 \\
77.3 \pm 0.9 \\
84.0 \pm 2.4 \\
91.2 \pm 1.2 \\
86.8 \pm 0.9 \\
94.6 \pm .7 \\
100.8 \pm .6 \\
90.8 \pm 1.0 \\
83.3 \pm 2.2 \\
\end{array}$ & $\begin{array}{l}83.6 \pm 1.3 \\
80.7 \pm 0.3 \\
79.9 \pm .9 \\
86.1 \pm .8\end{array}$ & $\begin{array}{l}117.6 \pm 0.6 \\
119.0 \pm .3 \\
105.6 \pm .3 \\
0\end{array}$ & $\begin{array}{l}61.2 \pm 0.1 \\
67.6 \pm .1 \\
66.1 \pm .1 \\
64.3 \pm .1 \\
65.9 \pm .1\end{array}$ & $\begin{array}{l}154 \pm 0.8 \\
156 \pm .5 \\
140 \pm .6 \\
137 \pm .8 \\
140 \pm .8\end{array}$ & $\begin{array}{l}282 \pm 1.0 \\
268 \pm 1.4 \\
258 \pm 0.6 \\
283 \pm .5 \\
262 \pm .9\end{array}$ \\
\hline Average $(\mathrm{cu} \mathrm{ft} / \mathrm{min}) / \mathrm{sq} \mathrm{ft} \ldots$ & 88.6 & 82.6 & 114.1 & 65.0 & 145 & 271 \\
\hline $\begin{array}{l}\text { Coefficient of variation, per- } \\
\text { cent }\end{array}$ & 8.1 & 3.8 & 6.1 & 3.5 & 5.7 & 3.9 \\
\hline
\end{tabular}

The three parachute cloths, materials I, II, and III in the tables, were also tested using (a) the beveled ring without the clamp, (b) an embroidery ring with the clamp, and (c) the embroidery ring without the clamp. The three blankets, materials IV, V, and VI in the tables, were also tested using (a) the beveled ring without the clamp and (b) the clamp without the beveled ring. These materials were tested for each method of mounting at the same locations and the same number of tests were made at each location, as reported in table 2. The average of the measurements on each material for each method of mounting and the coefficient of variation in percent are given in table 3. The coefficient of variation is the number within the parentheses.

TABLE 3.-Result showing effect of method of mounting on the air permeability

[The average air permeability, cubic feet per minute per square foot of fabric for a pressure drop of 0.5 in of water across the fabric, is shown with the coefficient of variation in percent in parentheses]

\begin{tabular}{|c|c|c|c|c|c|}
\hline \multirow[b]{2}{*}{ Material designation } & \multicolumn{5}{|c|}{ Method of mounting } \\
\hline & $\begin{array}{l}\text { Beveled ring } \\
\text { and clamp }\end{array}$ & Beveled ring & Clamp & $\begin{array}{l}\text { Embroidery } \\
\text { ring and } \\
\text { clamp }\end{array}$ & $\begin{array}{c}\text { Embroidery } \\
\text { ring }\end{array}$ \\
\hline $\begin{array}{l}\text { II } \\
\text { IIII. } \\
\text { IV } \\
\text { V } \\
\text { VII }\end{array}$ & $\begin{array}{r}88.6(8.1) \\
82.6(3.8) \\
114.1(6.1) \\
65.0(3.5) \\
145 \quad(5.7) \\
271 \quad(3.9)\end{array}$ & $\begin{array}{rr}91.6 & (9.0) \\
86.0 & (3.4) \\
116.1 & (4.6) \\
106 & (2.7) \\
175 & (4.9) \\
322 & (3.0)\end{array}$ & $\begin{array}{r}65(6.3) \\
144(5.6) \\
270(4.0)\end{array}$ & \begin{tabular}{rr}
$88.5(11.3)$ \\
87.2 & $(5.0)$ \\
115.2 & $(4.9)$ \\
\hdashline
\end{tabular} & $\begin{array}{r}90.0(11.5) \\
88.8(4.5) \\
116.4 \quad(5.1) \\
\\
\hdashline\end{array}$ \\
\hline
\end{tabular}

The results on the three parachute fabrics, designations I, II, and III, were not affected significantly by the four methods of mounting. The results on the three blankets, designations IV, V, and VI, were affected significantly by the method of mounting. The air permeability was found to be over 20 percent higher when the clamp was not used. This increase was caused by air leaking through the fabric which surrounds the opening of the orifice when the clamp was not used. The edge leakage was less than 0.1 percent for blanket VI when the clamp was used. 
These results show that the clamp must be used when compressible materials, such as blankets, are tested for air permeability. It is good practice to use the clamp when testing less compressible materials. The beveled ring is an aid in mounting limp fabrics. It can be used on fabrics which vary greatly in thickness. In testing stiff fabrics, which offer considerable resistance to the deformation produced by the ring, it is better to dispense with the ring and to use the clamp alone.

Several fabrics were tested on six instruments of the new model. The results obtained with the different instruments for the same fabric were within 2 percent of the average. Most of this variation is ascribable to the variation within the fabrics.

Washington, February 27, 1942. 